\title{
Role of Therapeutic Drug Monitoring of Voriconazole in the Treatment of Invasive Fungal Infections
}

\author{
I fan Kuo and Mary H H Ensom
}

\begin{abstract}
Background: Voriconazole is a broad-spectrum, second-generation triazole antifungal agent with demonstrated efficacy in the treatment of invasive fungal infections caused by Aspergillus spp. and Candida spp. Given the characteristically poor prognosis of patients with invasive fungal infections and the protracted duration of treatment required, therapeutic monitoring of voriconazole is, in theory, an attractive method to optimize antifungal therapy.
\end{abstract}

Objective: To determine the utility of therapeutic drug monitoring for voriconazole.

Methods: A previously published decision-making algorithm was used to assess the currently available literature on therapeutic drug monitoring of voriconazole.

Results: Several analytical methods can be used to quantify plasma or serum concentrations of voriconazole. Reasons for therapeutic monitoring of this drug include wide variability both within and between individuals secondary to drug properties, drug-drug interactions, and disease states. Furthermore, voriconazole follows nonlinear pharmacokinetics with saturable hepatic clearance. Another potential factor in favour of therapeutic drug monitoring for voriconazole is genetic polymorphism of CYP2C19, whereby patients who are homozygous for poor metabolism (about 19\% of non-Indian Asians) can have 4-fold greater exposure to voriconazole. The concentrations of this drug are also greater in patients with hepatic impairment. Drug-drug interactions with other substrates of CYP2C9, CYP2C19, and CYP3A4 can also alter voriconazole concentrations. However, the correlations between plasma concentrations of voriconazole and its efficacy and toxicity are not well defined. Although lower and upper target thresholds of $0.25-2 \mathrm{mg} / \mathrm{L}$ and $4-6 \mathrm{mg} / \mathrm{L}$, respectively, have been suggested, studies to date have not been appropriately designed or powered to reveal any definitive association.

Conclusions: Routine therapeutic drug monitoring of voriconazole is not recommended except in certain circumstances, such as lack of response to therapy or evidence of toxicity, in which case selective monitoring of voriconazole concentrations may be of clinical utility.

Key words: voriconazole, therapeutic drug monitoring, pharmacokinetics, antifungal, invasive fungal infection

\section{RÉSUMÉ}

Contexte : Le voriconazole est un antifongique triazolé de deuxième génération à large spectre efficace dans le traitement des infections fongiques envahissantes causées par les espèces Aspergillus et Candida. Vu le sombre pronostic caractéristique des patients atteints d'infections fongiques envahissantes et la durée prolongée du traitement, le suivi thérapeutique pharmacologique du voriconazole est, en théorie, un moyen attrayant d'optimiser le traitement antifongique.

Objectif : Déterminer l'utilité du suivi thérapeutique pharmacologique du voriconazole.

Méthodes : Un algorithme de prise de décision publié a été utilisé pour évaluer la documentation actuellement disponible sur le suivi thérapeutique pharmacologique du voriconazole.

Résultats : Plusieurs méthodes analytiques peuvent servir à quantifier les concentrations sériques ou plasmatiques de voriconazole. Les raisons de recourir au suivi thérapeutique pharmacologique de ce médicament sont notamment la grande variabilité intra et interindividuelle attribuable aux propriétés du médicament, aux interactions médicament-médicament et aux affections. De plus, le voriconazole a un comportement pharmacocinétique non linéaire en raison d'une clairance hépatique saturable. Un autre facteur potentiellement en faveur du suivi thérapeutique pharmacologique du voriconazole est le polymorphisme génétique du CYP2C19 qui, chez les patients homozygotes ayant un faible métabolisme (environ 19\% des Asiatiques non Indiens), peut entraîner une exposition au voriconazole quatre fois supérieure. Les concentrations de ce médicament sont également supérieures chez les patients atteints d'insuffisance hépatique. Les interactions médicamentmédicament avec d'autres substrats du CYP2C9, du CYP2C19 et du CYP3A4 peuvent également modifier les concentrations de voriconazole. Cependant, les corrélations entre les concentrations plasmatiques de voriconazole et l'efficacité et la toxicité de ce médicament ne sont pas clairement définies. Bien qu'on ait suggéré des seuils inférieurs et supérieurs cibles de 0,25 à $2 \mathrm{mg} / \mathrm{L}$ et de 4 à $6 \mathrm{mg} / \mathrm{L}$, respectivement, les études menées à ce jour ne sont ni correctement conçues, ni suffisamment puissantes pour révéler une association définitive.

Conclusions : Le suivi thérapeutique pharmacologique systématique du voriconazole n'est pas recommandé, sauf dans certaines circonstances, comme en absence de réponse au traitement ou en présence de signes de toxicité, auxquels cas la surveillance sélective des concentrations de voriconazole peut s'avérer utile sur le plan clinique.

Mots clés : voriconazole, suivi thérapeutique pharmacologique, pharmacocinétique, antifongique, infection fongique envahissante

[Traduction par l'éditeur] 


\section{INTRODUCTION}

Tnvasive fungal infections are associated with substantial 1 morbidity and mortality in immunocompromised patients, particularly high-risk populations, such as those undergoing solid organ and bone marrow transplantation, receiving chemotherapy, with HIV-positive status, and/or receiving longterm immunosuppressant therapy. ${ }^{1-7}$ Of concern, the incidence of invasive fungal infections has been increasing, along with an epidemiologic shift., ${ }^{4,6-8}$ Although Candida spp. remain the most common yeasts isolated in cases of fungal infection, there has been a general increase in candidiasis caused by non-albican Candida. ${ }^{4,6,8}$ Aspergillus spp. are the most common moulds recovered from immunocompromised patients with invasive fungal infections, but Fusarium spp., Scedosporium spp., Penicillium spp., and Zygomycetes are also on the rise. ${ }^{3,4,8}$ It has been proposed that these changes in incidence and epidemiologic pattern have occurred largely because of increasing numbers of immunocompromised patients, along with use of antineoplastic and immunosuppressive agents, broad-spectrum antibiotics, prosthetic devices and grafts, and more aggressive surgical interventions. ${ }^{4}$ Invasive aspergillosis is a fungal infection with an incidence of $11 \%$ to $13 \%$ in high-risk populations, an overall case fatality rate of $58 \%$, and a fatality rate as high as $90 \%$ among patients undergoing bone marrow transplant and those with infections involving the central nervous system. ${ }^{9,10}$ Current pharmacologic options for prophylaxis and treatment of invasive fungal infections include the polyenes, azoles, nucleoside analogues, and echinocandins. ${ }^{10,11}$

Formerly known as UK-109,496, the drug voriconazole is a broad-spectrum, second-generation triazole antifungal agent with in vitro activity against Candida spp., Aspergillus spp., Fusarium spp., Scedosporium spp., and Cryptococcus neoformans. ${ }^{10-14}$ At the cellular level, voriconazole depletes the fungal cells of ergosterol and causes accumulation of methylated sterol intermediates via inhibition of the P450-dependent enzyme lanosterol $14 \alpha$-demethylase, which leads to disruption of cell-wall synthesis and interruption of fungal cell growth. ${ }^{12-14}$ Voriconazole has been studied as a treatment option for both yeast and mould infections, including esophageal candidiasis, invasive candidiasis, and invasive aspergillosis. ${ }^{10,13,14}$ It also has demonstrated efficacy against the less common fungal infections such as fusariosis and scedosporiosis. ${ }^{10,13-15}$ In the most recent clinical practice guideline of the Infectious Diseases Society of America (IDSA), voriconazole has replaced amphotericin $\mathrm{B}$ as the first-line agent recommended for treatment of invasive aspergillosis. ${ }^{16}$

Voriconazole is available in both IV and oral formulations, and its pharmacokinetic properties have been studied in both healthy volunteers and immunocompromised patients. ${ }^{12,13}$ Recommended dosing regimens for both adult and pediatric patients with invasive candidiasis (12 years of age and older and weighing more than $40 \mathrm{~kg}$ ) include 2 loading doses of $6 \mathrm{mg} / \mathrm{kg}$ IV $12 \mathrm{~h}$ apart, followed by 3-4 mg/kg IV q12h or $200 \mathrm{mg}$ PO twice daily. ${ }^{11,17}$ In light of the expected accelerated metabolic clearance among children 2 to 11 years of age, the European Medicines Agency recommends a maintenance dosage of $7 \mathrm{mg} / \mathrm{kg}$ twice daily in this population. ${ }^{18}$ Pharmacokinetic data from healthy persons given voriconazole demonstrate high oral bioavailability (between $90 \%$ and $96 \%$ ). ${ }^{13,19}$ The time to maximum plasma concentration $\left(T_{\max }\right)$ for voriconazole ranges from 1.43 to $1.81 \mathrm{~h}$, with a corresponding maximum plasma concentration $\left(C_{\max }\right)$ of 1.88 to $5.27 \mathrm{mg} / \mathrm{L} .{ }^{20}$ In one study, bioavailability and $T_{\max }$ were comparable in 18 patients with invasive candidiasis, but the data for those patients were less accurate than those obtained from healthy volunteers because of fewer sampling time points (i.e., 6 versus 12, respectively) over a 12 -h period. ${ }^{12}$

Plasma protein binding for voriconazole is estimated to be $58 \%$, and such binding is independent of the concentration of the drug in the plasma. ${ }^{13}$ Voriconazole has a volume of distribution of $4.6 \mathrm{~L} / \mathrm{kg}$ and is distributed extensively into the tissues, including the vitreous fluid, aqueous humor, cerebrospinal fluid, and bones. ${ }^{12,21-23}$

Voriconazole is highly metabolized by CYP2C19, CYP2C9, and, to a lesser extent, CYP3A4 into at least 8 different metabolites, all of which exhibit minimal antifungal activity. ${ }^{17}$ Less than $2 \%$ of the drug is excreted unchanged in urine $^{13} ; 80 \%$ of the drug's metabolites are eliminated in urine, and the remainder is excreted through the fecal route. ${ }^{12}$ The terminal half-life is estimated at between 6 and $12{\mathrm{~h} .{ }^{10}}^{0}$

Variability in plasma concentration of voriconazole both within and between individuals is high. ${ }^{17,24-26}$ This characteristic can be attributed to several pharmacokinetic factors, including saturable hepatic clearance, age, genetic polymorphism of CYP2C19, drug-drug interactions, hepatic dysfunction, and variation in absorption. In view of the unpredictability of plasma concentrations, therapeutic drug monitoring (TDM) for voriconazole has been proposed as a way to ascertain clinical efficacy and minimize toxic effects. ${ }^{8,25-32}$ In their recent review articles, Smith and others ${ }^{33}$ and Hope and others ${ }^{34}$ addressed the topic of TDM for antifungal agents, discussing voriconazole briefly. Brüggemann and others ${ }^{35}$ and Howard and other ${ }^{36}$ also discussed the role of TDM for voriconazole specifically, the latter focusing exclusively on invasive aspergillosis. The review by Brüggemann and others ${ }^{35}$ was the most comprehensive to date and provided extensive interpretation of current data regarding the relation between concentrations of voriconazole and efficacy and toxic effects in patients. Although most previous authors have arrived at similar conclusions regarding the use of TDM to determine the efficacy and toxic effects of voriconazole, to the current authors' knowledge, there has been no discussion of the most fundamental issues in 
evaluating TDM, including its practical applicability in a clinical environment. Thus, a systematic approach to determining the utility of TDM for voriconazole was warranted.

The objective of this review was to assess, using a previously published 9-step decision-making algorithm (Figure 1), ${ }^{37}$ the currently available literature with a view to determining the utility of TDM for voriconazole.

\section{SEARCH STRATEGY}

A literature search of the following databases was performed from the date of inception to December 2008 to identify relevant articles: MEDLINE (from 1950), EMBASE (from 1980), BIOSIS Previews (from 1969), International Pharmaceutical Abstracts (from 1970), Web of Science (from
1965), and Cochrane Central Register of Controlled Trials. The search was limited to English-language studies involving humans and used the following search terms: "voriconazole", "antifungals", "therapeutic drug monitoring", "drug levels", "drug monitoring", "invasive fungal infections", "invasive candidiasis", and "aspergillosis". Bibliographies of the relevant articles were also searched by hand to identify additional relevant literature.

\section{SPECIFIC INDICATIONS}

The first question to be answered in determining the utility of TDM for voriconazole is whether the patient is taking the best drug for his or her specific subpopulation (disease state) and specific indication. ${ }^{37}$

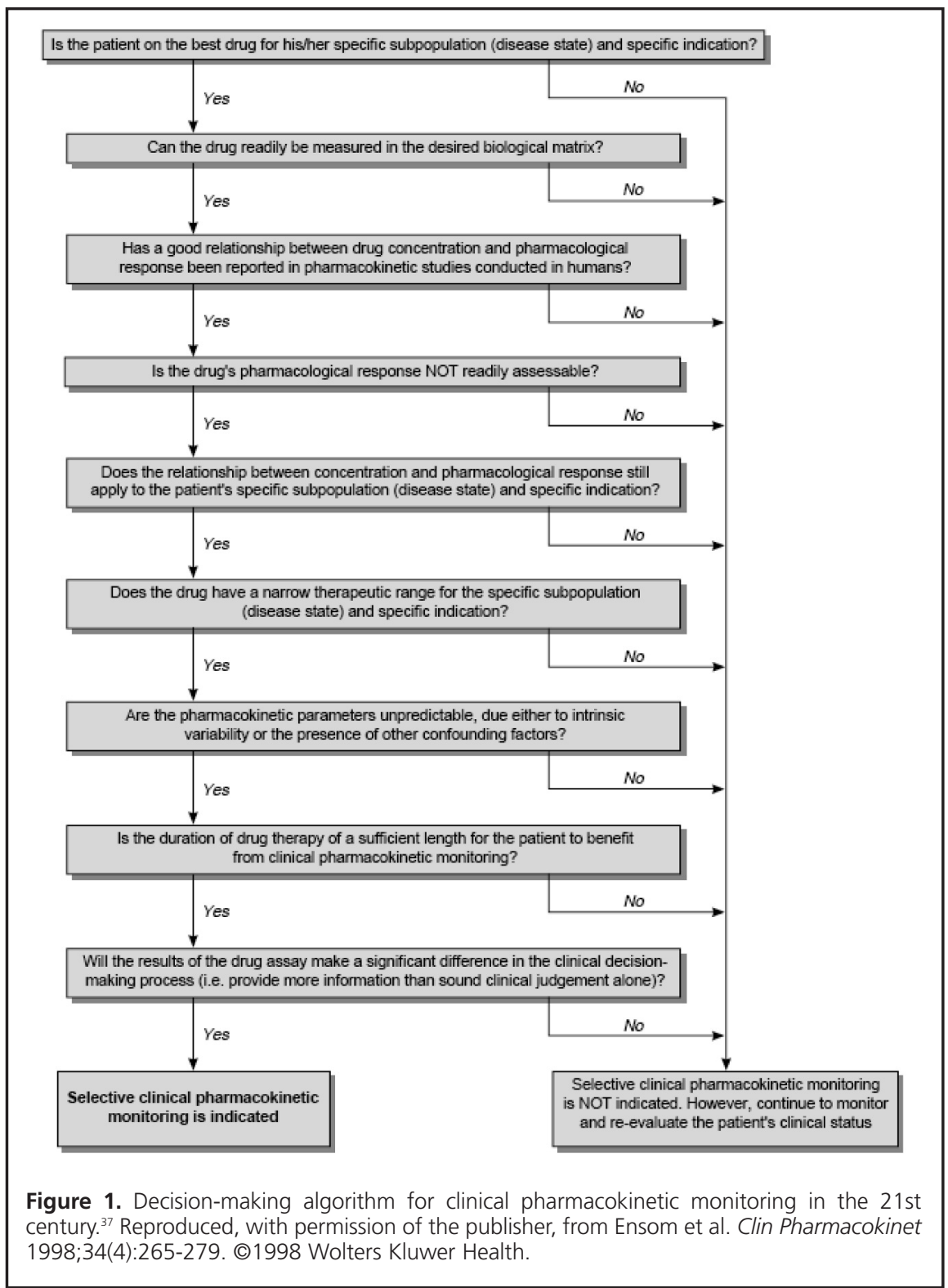


Voriconazole has been approved in North America for use in adults and in Europe for use in children. Current IDSA guidelines recommend voriconazole as a first-line agent for the treatment of invasive aspergillosis and as step-down oral therapy for certain cases of candidiasis. ${ }^{38}$ It is also indicated for the treatment of invasive fungal infections caused by Scedosporium spp. and Fusarium spp. ${ }^{14}$ The following discussion focuses on the major trials that have studied the use of voriconazole in invasive fungal infection, the majority of which enrolled immunocompromised patients.

\section{Aspergillosis}

The most important trial demonstrating the efficacy of voriconazole as primary treatment for invasive aspergillosis was a multicentre, randomized, nonblinded, non-inferiority trial published in 2002, which enrolled 277 immunocompromised patients with proven or probable invasive aspergillosis. ${ }^{39}$ The patients were randomly assigned to receive either voriconazole (6 mg/kg IV q12h for 2 doses, then $4 \mathrm{mg} / \mathrm{kg}$ IV q12h for a minimum of 7 days, followed by $200 \mathrm{mg}$ PO bid) or amphotericin B (1-1.5 mg/kg IV daily). In a modified intention-to-treat analysis, the survival rates at 12 weeks were $71 \%$ in the voriconazole group and $58 \%$ in the amphotericin B group (hazard ratio [HR] 0.59, 95\% confidence interval [CI] $0.40-0.88 ; p=0.02)$. Fewer adverse events were observed in the voriconazole group, with the exception of visual disturbances (which had rates of $44.8 \%$ for the voriconazole group and $4.3 \%$ for the amphotericin B group, $p<0.001$ ).

Similar results were obtained in an open, nonblinded, noncomparative trial published in the same year. ${ }^{24}$ In that trial, $48 \%$ of the patients receiving voriconazole met the primary efficacy end point of a good response (defined as complete or partial response, as determined by clinical and radiographic change). Almost half of the patients received voriconazole as salvage therapy, whereas the remainder received it as primary treatment. The incidence of visual disturbance was $11 \%$, lower than the $44.8 \%$ in the study by Herbrecht and others. ${ }^{39} \mathrm{~A}$ similar trial performed later involved 36 patients with subacute invasive and chronic pulmonary aspergillosis who were receiving voriconazole as primary or salvage therapy. ${ }^{40}$ The rates of therapeutic response and toxic effects were comparable to those observed by Denning and others. ${ }^{24}$ Smaller observational studies and case reports have also demonstrated the efficacy of voriconazole for treatment of invasive aspergillosis in specific populations of immunocompromised patients. ${ }^{41,42}$

The only literature to date that has investigated the role of voriconazole for treatment of invasive aspergillosis in patients without immunocompromise was a retrospective trial involving patients with chronic necrotizing pulmonary aspergillosis. ${ }^{43}$ In that study, $58 \%$ of the patients had a response to voriconazole by the end of follow-up, after a median duration of treatment of 9 months.

\section{Candidiasis}

Two large trials investigated the role of voriconazole in patients with candidiasis. The first, a non-inferiority study, enrolled 391 immunocompromised adult patients with esophageal candidiasis, who were randomly assigned to receive either voriconazole or fluconazole as oral therapy. ${ }^{44}$ On the basis of a per-protocol population analysis at the end of therapy, oral voriconazole was non-inferior to fluconazole in terms of treatment success rate (defined as patients with cure or improvement, as determined by esophagoscopy). ${ }^{44}$

The second study, a randomized, multicentre, nonblinded, non-inferiority trial, compared voriconazole with amphotericin $\mathrm{B}$ for the treatment of invasive candidiasis in 422 nonneutropenic patients. ${ }^{45} \mathrm{~A}$ modified intention-to-treat analysis showed no significant difference between the 2 groups in terms of the primary end point for efficacy, success rate at 12 weeks after the end of therapy. Adverse renal events were significantly lower in the voriconazole group than in the amphotericin B group ( $8 \%$ versus $91 \%, p=0.0002$ ), as were chills (3\% versus $8 \%, p=0.03)$.

\section{Treatment of Rare Fungal Infections and/or Salvage Therapy}

The efficacy of voriconazole as treatment for refractory or rare invasive fungal infections has been documented in several case reports and small observational studies. The largest trial evaluating voriconazole for this indication was an open, noncomparative, multicentre study conducted by Perfect and others. ${ }^{15}$ A total of 301 patents were enrolled, the majority of whom were immunocompromised and received voriconazole as salvage therapy. The efficacy rates (defined as a global response based on a composite of clinical, mycological, radiological, and serological responses) were $43.7 \%$ for aspergillosis, $57.5 \%$ for candidiasis, $38.9 \%$ for cryptococcosis, $45.5 \%$ for fusariosis, and $30 \%$ for scedosporiosis. A smaller observational study evaluating voriconazole as salvage therapy for refractory invasive candidiasis reported similar response rates. ${ }^{46}$

\section{Empiric Therapy in Fever and Neutropenia}

At present, voriconazole is not indicated for empiric use in patients with neutropenia, primarily because of a non-inferiority trial that had a significantly higher proportion of discontinuation in the group receiving voriconazole (secondary to lack of response to therapy) than in the group receiving liposomal amphotericin B. ${ }^{47,48}$ However, diagnostic tools have improved since publication of the original study, ${ }^{47}$ and future diagnostic techniques may allow more rapid identification of patients with neutropenia who are at risk of aspergillosis and who may benefit from empiric treatment with voriconazole. ${ }^{49}$ 


\section{Pediatric Patients}

The use of voriconazole in pediatric patients has been described in several case reports and observational studies. ${ }^{50-54}$ In one study, treatment success (as determined by clinical, radiographic, and mycological evidence) was 45\% among 58 children (ranging in age from 9 months to 15 years) with aspergillosis, candidiasis, or scedosporiosis. ${ }^{50}$ Cesaro and others $^{51,52}$ conducted 2 small observational studies in pediatric patients with invasive fungal infections. In the first of these studies, 7 of the 8 patients had a response to voriconazole given as rescue or maintenance therapy. ${ }^{51}$ In the second study, 5 of 7 patients with invasive aspergillosis had a response to treatment with voriconazole. ${ }^{52}$ Kolve and others ${ }^{53}$ studied 37 immunocompromised pediatric patients with invasive fungal infections and found that $86 \%$ of the patients with probable or proven infections and $100 \%$ of those with possible infections had a response to treatment and their condition remained stable. In a case series involving patients with cystic fibrosis and recurrent allergic bronchopulmonary aspergillosis, Hilliard and others ${ }^{54}$ reported a response to voriconazole therapy.

\section{DRUG ASSAY}

The second question in the algorithm for determining the appropriateness of TDM is whether the drug can be readily measured in the desired biological matrix. ${ }^{37}$

Data on drug concentrations can be used to guide clinical decision-making only if they are reliable. An ideal analytic assay is highly sensitive, specific, precise, accurate, rapid, and afford- able. Several analytic methods have been developed to quantify voriconazole concentration in human plasma or serum (Table 1). ${ }^{55-68}$ Most of these assays use high-performance liquid chromatography (HPLC) methods either with ultraviolet (UV) detection or coupled with mass spectrophotometry. ${ }^{56-68}$ Other methods such as microbiological assays have also been investigated. ${ }^{55,56}$

Some of the HPLC methods developed for quantifying voriconazole in plasma are limited by long turn-around time, complex procedures, and/or narrow quantification range that does not adequately reflect concentrations of voriconazole in the clinical setting. . $859,61,64,66,68$ Although no therapeutic range has been decisively established, target concentrations reported in the literature have ranged from less than 0.5 to greater than $10 \mathrm{~g} / \mathrm{mL} \cdot{ }^{14,17}$ A quantification range between 0.25 and $15 \mathrm{mg} / \mathrm{L}$, as suggested by Pascual and others, ${ }^{55}$ appears reasonable.

Various methods combining HPLC with tandem mass spectrometry (TMS) have also been evaluated for measuring concentrations of voriconazole in plasma. ${ }^{66-68}$ These methods have the advantages of small sample volume requirements, high sensitivity, and short turn-around time. However, they are, in general, expensive and not readily available at some institutions. ${ }^{60}$

Bioassays are an attractive option because they are relatively low in cost. However, they have the disadvantages of low sensitivity, long turn-around time, and potential cross-reactivity of the inactive metabolite in the bioassay. In one HPLCTMS validation study, the dynamic range of the bioassay was inadequate and interassay reproducibility was lacking. ${ }^{67}$

Table 1. Analytic Methods for Voriconazole in Plasma or Serum

\begin{tabular}{|c|c|c|c|c|c|}
\hline \multirow[b]{2}{*}{ Study } & \multirow[b]{2}{*}{$\begin{array}{l}\text { LLOQ and Max } \\
(\mu \mathrm{g} / \mathrm{mL})\end{array}$} & \multirow[b]{2}{*}{$\begin{array}{c}\text { Sample } \\
\text { Volume }(\mathrm{mL})\end{array}$} & \multicolumn{2}{|c|}{$\% \mathrm{CV}$} & \multirow[b]{2}{*}{ Accuracy (\%) } \\
\hline & & & Interday & Intraday & \\
\hline \multicolumn{6}{|l|}{ Bioassay } \\
\hline Pascual et al. ${ }^{55}$ & $0.2,6$ & 0.5 & $2.2-6.1$ & 5.0-10.3 & 89.0-99.2 \\
\hline Perea et al. ${ }^{56}$ & $0.25,20$ & 0.01 & $<13$ & $<3$ & $98.7-101.3$ \\
\hline \multicolumn{6}{|l|}{ HPLC-UV } \\
\hline Chhun et al. ${ }^{57}$ & $0.2,10$ & 0.1 & $3.73-10.1$ & $3.48-10.4$ & $90.5-101.5$ \\
\hline Gage and Stopher ${ }^{58}$ & $0.05,10$ & 0.5 & $0.75-4.7$ & $2.6-13$ & $97.0-105.0$ \\
\hline Khoschsorur et al. ${ }^{59}$ & $0.1,8$ & 1.0 & $2.1-6.6$ & $2.6-9.3$ & $95.7-104.3$ \\
\hline Langman et al. ${ }^{60}$ & $0.1,20$ & 0.5 & $2.5-7.7$ & $4.4-6.8$ & NR \\
\hline Péhourcq et al. ${ }^{61}$ & $0.2,7$ & 0.01 & $4.0-5.8$ & $4.0-6.6$ & $92.5-98.6$ \\
\hline Pennick et al. ${ }^{62}$ & $0.2,10$ & 0.5 & $7.8-16$ & $1.5-15.7$ & $82.6-113.1$ \\
\hline Pascual et al. ${ }^{55}$ & $0.125,25$ & 0.5 & $4.3-6.3$ & $3.9-6.6$ & $89.8-100.7$ \\
\hline Perea et al ${ }^{56}$ & $0.2,10$ & 0.5 & $<4$ & $<2.5$ & $99.2-100.8$ \\
\hline Shihabi63 & $0.4,10$ & 0.05 & $N R$ & $N R$ & $74.5-93.4$ \\
\hline Stopher and Gage ${ }^{64}$ & $0.005,3$ & 0.7 & $5.0-5.9$ & $0.8-8.4$ & $93.2-100.0$ \\
\hline Wenk et al. ${ }^{65}$ & $0.1,10$ & 0.25 & $1.58-6.06$ & $0.34-3.8$ & $99.5-106.0$ \\
\hline \multicolumn{6}{|l|}{ HPLC-TMS } \\
\hline Egle et al. ${ }^{66}$ & $0.05,5$ & 0.005 & $7.1-16.57$ & $3.65-6.81$ & $97.1-118.6$ \\
\hline Keevil et al. ${ }^{67}$ & $0.1,20$ & 0.01 & $4.8-17.0$ & $3.6-10.0$ & $82.0-105.0$ \\
\hline Vogeser et al. ${ }^{68}$ & $0.078,5$ & 0.1 & NR & $1.0-0.7$ & $94.0-107.0$ \\
\hline
\end{tabular}

CV = coefficient of variation, HPLC-TMS = high-performance liquid chromatography with tandem mass spectrometry,

HPLC-UV = high-performance liquid chromatography with ultraviolet detection, LLOQ = lower limit of quantification,

Max = maximum concentration quantified, NR = not reported. 
Two studies provided stability data, suggesting that plasma samples obtained for quantification of voriconazole are stable, with minimal change in concentration after 2 or 3 freeze-thaw cycles and storage at $-25^{\circ} \mathrm{C}$ for up to 14 months. ${ }^{60,64}$ Stability was also good (i.e., percent coefficient of variation [CV] less than $6.6 \%$, accuracy $91.2 \%$ ) when samples were stored at room temperature for $24 \mathrm{~h}$ in daylight or in the dark. ${ }^{61}$

It appears that HPLC-UV may be the most acceptable analytic method for measuring voriconazole. Nevertheless, high costs and the requirement for specialized equipment mean that the assay is not readily accessible to many health care institutions.

\section{DRUG CONCENTRATION AND PHARMACOLOGIC RESPONSE}

The third consideration in deciding on TDM for voriconazole is whether a good relationship between drug concentration and pharmacologic response has been reported in pharmacokinetic studies conducted in humans. ${ }^{37}$

Few studies to date have assessed the potential correlation between plasma concentrations of voriconazole and pharmacologic response in terms of efficacy and toxic effects (Table 2). ${ }^{13,18,2,24,28,29,53,69-71}$ The majority of these studies were small observational trials with high heterogeneity in terms of patient characteristics and sampling times for the voriconazole plasma samples. Although some of the data suggested a positive correlation between concentration of voriconazole and pharmacologic response, ${ }^{18,24,29}$ data from other studies did not support such a relationship. ${ }^{13,53}$

\section{Relation Between Concentration and Efficacy}

In a prospective, nonblinded, noncomparative multicentre trial, ${ }^{24} 122$ random samples were drawn from 137 patients for determination of plasma voriconazole concentration; the majority of these patients were immunocompromised and were receiving voriconazole as primary or salvage therapy for proven or probable invasive aspergillosis. Five of the patients had consistently low mean concentration of voriconazole $(<0.25 \mathrm{mg} / \mathrm{L})$. Three of these 5 patients had a failed response to therapy (defined as disease progression and death due to invasive aspergillosis, as determined by clinical, radiologic, and mycologic evidence), whereas the fourth patient had a stable response and the fifth had initial deterioration but later improvement when the dose was escalated. No difference in clinical outcomes was noted between patients with voriconazole concentrations between 0.5 and $1 \mathrm{mg} / \mathrm{L}$ and those with voriconazole concentrations above $1 \mathrm{mg} / \mathrm{L}$.

In a similar prospective observational study, 52 patients underwent TDM for voriconazole. ${ }^{29}$ A dosage adjustment scheme was followed to target trough concentrations between
1 and $5.5 \mathrm{mg} / \mathrm{L}$. Six (46\%) of the 13 patients with trough concentrations of $1 \mathrm{mg} / \mathrm{L}$ or less had no response to therapy, whereas only $5(13 \%)$ of the 39 patients with trough concentrations above $1 \mathrm{mg} / \mathrm{L}$ had no response $(p=0.02)$. All 6 of the patients with no response and trough concentrations of $1 \mathrm{mg} / \mathrm{L}$ or less experienced improvement in outcomes after dose escalation. In a retrospective study, Smith and others ${ }^{18}$ used classification and regression tree modelling to determine that the pharmacokinetic-pharmacodynamic (PK-PD) break point for clinical response was $2.05 \mathrm{mg} / \mathrm{L}$. Concentrations of voriconazole above the determined break point were associated with $100 \%$ clinical response, whereas $44 \%$ of those below the break point had disease progression.

Contrary to the positive associations reported in these studies, Kolve and others ${ }^{53}$ found no correlation between trough concentrations of voriconazole and clinical outcomes in a group of 37 pediatric patients. Pfizer, the manufacturer of voriconazole, also concluded that concentrations of the drug were not predictive of clinical efficacy, on the basis of 6 of the 10 phase II and phase III therapeutic trials sponsored by the company. ${ }^{13}$ However, details on how the plasma samples had been collected and analyzed were not available and therefore could not be assessed by the authors of the present review.

Most of the studies evaluating a possible association between concentration of voriconazole and clinical outcomes share similar shortcomings. The observational nature of their designs renders all of the trials underpowered to establish any conclusive causal effect between concentration of the drug and pharmacologic response. Also, the studies were largely heterogeneous in terms of patient populations and the sampling time for determination of plasma voriconazole. In one trial, only about half of the patients had proven or probable invasive aspergillosis. ${ }^{29}$ Lack of certainty about the diagnosis at baseline, coupled with unblinded study design, made definitive and unbiased assessment of treatment response difficult. Furthermore, the time frame for assessment of end points and patient follow-up were not specified in some studies. ${ }^{24,29}$ In many studies, the inclusion and exclusion criteria were not well described, which may have confounded interpretation of the observations. There is also the likelihood of high variability among the blood samples collected, given that they were not consistently drawn at specified times relative to dosing time. ${ }^{13,18,24}$ One major limitation of these studies was the apparent selection bias for TDM. For example, in the study by Pascual and others, ${ }^{29}$ patients who received voriconazole and underwent TDM were followed and analyzed prospectively, whereas those who received voriconazole without drug monitoring were assessed retrospectively. In that study, it was not clear how patients were selected for drug monitoring. As such, any positive association observed might have been due to selection bias in a nonrandomized study. On the whole, the 


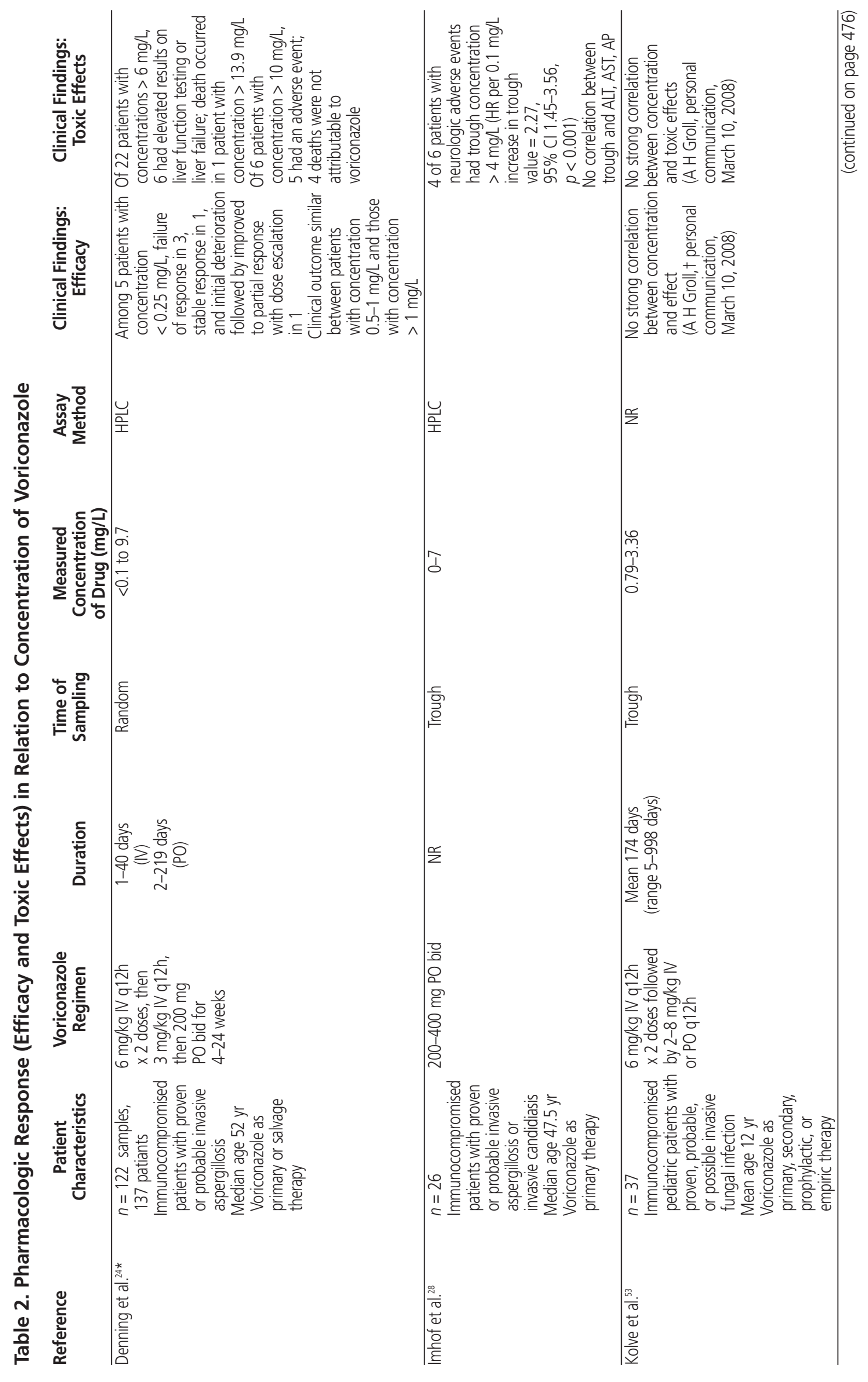




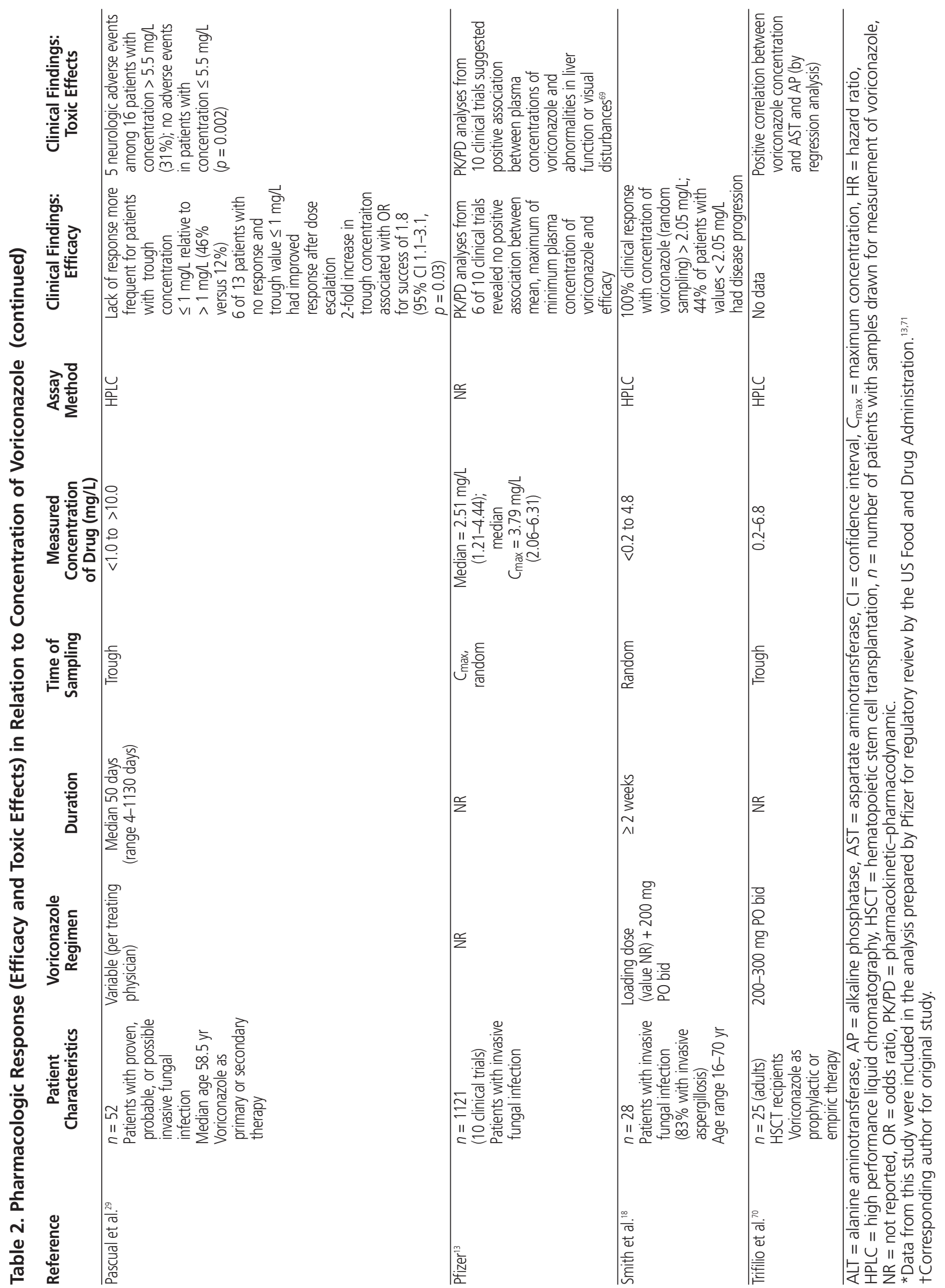


most important limitation common to the aforementioned trials $s^{13,18,24,29}$ lies in the variety of pharmacokinetic parameters used to predict clinical efficacy. Although Denning and others ${ }^{24}$ suggested the existence of a relationship between drug concentration and pharmacologic response, the purported correlation was based on random sampling for determination of voriconazole concentration. Pascual and others ${ }^{29}$ found a correlation between trough concentrations of voriconazole and clinical outcomes, but that result was refuted by Kolve and others, ${ }^{53}$ who also investigated trough concentrations of the drug.

\section{Relation Between Concentration and Toxic Effects}

Several studies and case reports have documented adverse effects potentially attributable to high concentrations of voriconazole in the plasma. Some of these studies are summarized in Table 2. The most frequently observed toxic effects of voriconazole are mild, such as headache, nausea, and vomiting, as well as elevated liver function tests, visual disturbances, and neurologic disturbances. ${ }^{17,72}$ The latter 3 adverse events have been suggested to correlate with plasma concentrations of voriconazole and are discussed in the next section.

In the study by Denning and others, ${ }^{24} 6$ of 22 patients with random plasma concentrations of voriconazole above $6 \mathrm{mg} / \mathrm{L}$ had elevated results on liver function testing or liver failure requiring discontinuation of therapy, per study protocol. The authors suggested that the death of one patient was attributable to a high plasma concentration of the drug (> $13.9 \mathrm{mg} / \mathrm{L}$ ). Six other patients had plasma concentrations above $10 \mathrm{mg} / \mathrm{L}$, and 5 of these experienced adverse events requiring discontinuation of therapy; however, it was not clear whether the adverse events were caused by the voriconazole. Elevated results on liver function testing were also observed in the study by Trifilio and others, ${ }^{70}$ who found a positive correlation between concentrations of voriconazole and of aspartate aminotransferase (AST) and alkaline phosphatase (AP) $(r=0.5, p=0.0009)$. However, no significant correlation was found with alanine aminotransferase (ALT), bilirubin, or creatinine. Pfizer's pooled analysis of 10 therapeutic trials revealed an association between concentration of voriconazole and AST, AP, and bilirubin, but not ALT. ${ }^{13,69}$ The authors ${ }^{69}$ concluded, however, that routine monitoring of voriconazole concentration to prevent elevated liver function was unlikely to add any clinical value relative to regular monitoring of liver function while patients were receiving voriconazole. Interestingly, 3 other studies did not reveal any association between concentration of voriconazole and liver function. . $8,29,53^{2}$

An association between elevated voriconazole concentration and visual disturbances (including enhanced or altered visual perception, blurred vision, changes in colour vision, and photophobia) was also observed in Pfizer's pooled analysis. ${ }^{13,69}$ Again, the authors ${ }^{69}$ concluded that routine monitoring of voriconazole concentrations is not warranted, despite the statistically significant positive correlation. This conclusion was based on the premise that visual disturbances represent, in general, a transient and mild effect that rarely necessitates discontinuation of voriconazole therapy. ${ }^{69}$

Two trials reported a possible association between high concentration of voriconazole and neurologic adverse events. ${ }^{31,29}$ Pascual and others ${ }^{29}$ recorded neurologic events (including confusion, agitation, pattern of toxic encephalopathy on electroencephalography, extrapyramidal signs, myoclonus, and visual and auditory hallucinations) in 5 of the 16 patients who had trough concentrations of voriconazole above $5.5 \mathrm{mg} / \mathrm{L}$; they observed no such effects in the group with concentrations of $5.5 \mathrm{mg} / \mathrm{L}$ or below $(p=0.002)$. In a small retrospective study, 4 of 6 patients with neurologic adverse events (including neuropathy, hallucinations, anxiety, insomnia, irritability, and impaired concentration) had trough concentrations of voriconazole above $4 \mathrm{mg} / \mathrm{L} .{ }^{28}$ This correlation was significant, with a hazard ratio of 2.27 per $0.1 \mathrm{mg} / \mathrm{L}$ increase in trough concentration (95\% CI 1.45-3.56, $p<0.001)$.

\section{Summary}

To date there is insufficient evidence to establish a definitive relation between concentration of voriconazole and pharmacologic response, in terms of either efficacy or toxic effects. Although some studies have suggested a high likelihood of therapeutic failure with low concentrations of voriconazole, the break point in the clinical response is unclear, if indeed one exists. Also, it is unknown which pharmacokinetic parameter is the best predictor of response. Many of the studies discussed above used trough concentrations of voriconazole as a benchmark, whereas some others used random concentrations or $C_{\max }$ values. Evidence also suggests a possible correlation between high concentrations of voriconazole and toxic effects. These studies, however, had substantial shortcomings. Furthermore, the clinical significance of such a relation must be considered, if one does exist. As Tan and others ${ }^{69}$ pointed out, routine TDM of voriconazole to prevent elevation of liver function and visual disturbance has minimal impact in therapeutic decision-making in the clinical setting. Conversely, as suggested by Imhof and others ${ }^{28}$ and by Pascual and others, ${ }^{29}$ TDM may be warranted in cases of neurologic adverse events caused by high concentrations of voriconazole. Nevertheless, the potential causal association and a clinically relevant target concentration must be established to guide clinical practice.

\section{EVALUATION OF RESPONSE}

The next question to be considered is whether the drug's pharmacologic response is not readily assessable, ${ }^{37}$ in terms of both efficacy and toxic effects. 


\section{Efficacy}

With the increasing prevalence of invasive fungal infections and the emergence of rare pathogens, the diagnosis of fungal infections remains challenging and controversial. Comorbidities such as immunosuppression and neutropenia in patients who are prone to this type of infection may complicate the diagnosis by masking key signs and symptoms.

A definitive diagnosis of invasive fungal infection usually requires positive findings on histopathologic or cytopathologic examination, with demonstrated growth of the offending pathogens. However, the results of such examinations can be falsely negative in patients who are already receiving antifungal therapy. Furthermore, certain patients may not be candidates for invasive diagnostic procedures because of concerns about hemodynamic instability. Thus, in most circumstances, the diagnosis of invasive fungal infections is based largely on the likelihood of such an infection. Even then, there is no consensus on how the probability of infection should be derived and how this should guide therapy. The Invasive Fungal Infections Cooperative Group of the European Organization for Research and Treatment of Cancer has released an international consensus statement on defining opportunistic invasive fungal infections; however, the guideline is intended for research purposes and for use with immunocompromised patients with cancer and hematopoietic stem cell transplantation. ${ }^{73}$

The recommended approach to monitoring therapeutic response in patients with invasive fungal infections is to regularly assess the clinical, mycological, radiographic, or histopathologic signs and symptoms that were positive at the time of diagnosis. ${ }^{16}$ This may involve serial computed tomography of the chest for patients with invasive pulmonary aspergillosis or repeat biopsy of the infection site. A composite of parameters should be adopted, instead of a single monitoring end point, because in some cases it may become difficult to differentiate infection from colonization.

\section{Toxic Effects}

Voriconazole is generally well tolerated, with the most frequently reported adverse events being visual disturbances, fever, rash, vomiting, nausea, headache, and diarrhea. ${ }^{13,17}$ The most common treatment-related adverse effects leading to discontinuation of therapy are elevated liver function, rash, and visual disturbances. ${ }^{13}$

In a postmarking analysis based on the French pharmacovigilance database, ${ }^{72}$ the most frequently reported adverse drug events among patients receiving voriconazole were liver function abnormalities (23\%), visual disturbances (18\%), skin rashes (17\%), neurologic disturbances (14\%), cardiovascular events (10\%), hematologic disorders (8\%), and renal disturbances (4\%). According to the Naranjo criteria, $84 \%$ of these events were classified as possible drug-related effects, $7 \%$ as probable, $5 \%$ as highly probable, and $4 \%$ as doubtful.

\section{USE IN SPECIAL POPULATIONS}

At this point, it is important to reassess whether the relationship between concentration and pharmacologic response still applies to the patient's specific subpopulation (disease state) and specific indication. ${ }^{37}$

\section{CYP2C19 Genotype}

Genetic polymorphism of CYP2C19, the primary metabolizing isoenzyme of voriconazole, was found to contribute to the wide variation in plasma concentrations of voriconazole between individuals. ${ }^{13,71,74}$ Patients who were homozygous for poor metabolism had 4-fold greater exposure to the drug. ${ }^{13,71,74}$ The incidence of homozygosity for poor metabolism is approximately $2 \%$, and is reported to be as high as $19 \%$ among non-Indian Asians. ${ }^{1726,75}$ However, wide variability was observed within each genotype in those studies. The clinical implications, if any, of CYP2C19 genetic polymorphism in the clinical setting are unknown, as these were not considered in the clinical trials.

\section{Renal Dysfunction}

The pharmacokinetics of both single-dose and multipledose courses of voriconazole therapy have been studied in patients with mild to severe renal impairment. ${ }^{13}$ Clearance of voriconazole administered orally and intravenously did not appear to be affected by renal function, as shown in studies of single-dose $(200 \mathrm{mg})$ oral therapy and multiple-dose IV therapy $(6 \mathrm{mg} / \mathrm{kg}$ loading dose for 2 doses, then $3 \mathrm{mg} / \mathrm{kg}$ IV for 5.5 days). ${ }^{13}$ As such, no dose adjustments have been suggested for patients with renal dysfunction. However, the excipient cyclodextrin, which is used in the IV formulation of voriconazole, is known to accumulate in patients with creatinine clearance values less than $50 \mathrm{~mL} / \mathrm{min}$. Although the clinical significance of accumulation of this compound in patients with renal dysfunction is unclear, the drug manufacturer advises using the oral formulation of voriconazole if possible in this circumstance. ${ }^{17}$

A small study examined the pharmacokinetics of a single oral dose of voriconazole $(200 \mathrm{mg})$ given to 5 patients who were undergoing peritoneal dialysis. ${ }^{76}$ Less than $1 \%$ of the administered dose was recovered in the dialysate $24 \mathrm{~h}$ after dosing. The authors concluded, on the basis of minimal peritoneal clearance of voriconazole, that no dosing adjustment is needed for this patient population. However, this conclusion is limited by the small sample size and the use of a single dose. Given the saturable metabolism of voriconazole, caution should be used in applying the results of this study to patients who are receiving peritoneal dialysis therapy. 
Fuhrmann and others ${ }^{77}$ characterized voriconazole pharmacokinetics in patients receiving continuous venovenous hemodiafiltration (CVVHDF). A total of 9 patients, 1 of whom had underlying liver cirrhosis, received a standard IV loading dose of voriconazole, followed by a maintenance dose. Prefilter, postfilter, and ultradiafiltrate samples were drawn for determination of voriconazole concentration at the time of $C_{\max }$ and at the end of the dosing interval $\left(C_{\min }\right)$ following the first dose. The clearance of voriconazole via CVVHDF was low, and total clearance was in agreement with that reported in previously published studies, except for prolonged elimination half-life $(52 \mathrm{~h})$ and reduced total clearance $(4 \mathrm{~L} / \mathrm{h})$ in the patient with cirrhosis. On the basis of these data, the investigators recommended no dose adjustments for patients undergoing CVVHDF. Follow-up voriconazole concentrations (up to the third dose) were determined for only 3 patients; as such, drug accumulation cannot be ruled out. Further study is needed to guide dosing in this population.

\section{Hepatic Dysfunction}

In a pharmacokinetic study of single-dose voriconazole therapy $(200 \mathrm{mg}$ ) the area under the concentration-time curve (AUC) was 2.3 times higher for patients with chronic but stable hepatic impairment (Child-Pugh classes A and B) than for those with normal hepatic function. ${ }^{13} \mathrm{~A}$ downward dose adjustment study was carried out to compare the effect of multiple dosing of voriconazole between patients with cirrhosis (Child-Pugh class B), who were receiving $100 \mathrm{mg}$ PO twice daily, and patients with normal hepatic function, who were receiving $200 \mathrm{mg}$ PO twice daily. ${ }^{13}$ On the basis of the results of these 2 studies, the drug manufacturer now recommends that the maintenance dose for patients with hepatic dysfunction should be half of that indicated for individuals with normal hepatic function. ${ }^{13}$ No data are yet available for patients with severe hepatic impairment.

\section{Pediatric Patients}

Two pharmacokinetic studies were conducted in 35 immunocompromised children between 2 and 12 years of age. ${ }^{13,32}$ A population pharmacokinetic analysis performed in both studies indicated that the pharmacokinetic characteristics of voriconazole in children are best described with a linear model, unlike the nonlinear profile seen in adults. Pharmacokinetic simulations showed that a maintenance dosing regimen of $4 \mathrm{mg} / \mathrm{kg}$ IV q12h is needed to achieve AUC values similar to those seen in adults receiving $3 \mathrm{mg} / \mathrm{kg} \mathrm{q} 12 \mathrm{~h}$.

\section{THERAPEUTIC RANGE}

The next question to be answered is whether the drug has a narrow therapeutic range for the specific subpopulation (disease state) and specific indication. ${ }^{37}$
Although some studies suggest a possible correlation between plasma concentration of voriconazole and efficacy, no break points in clinical response for efficacy and safety have been formally established. The suggested lower threshold for the therapeutic range varies from less than $0.25 \mathrm{mg} / \mathrm{L}$ to as high as $2 \mathrm{mg} / \mathrm{L},{ }^{18,24}$ and the upper threshold (to avoid toxic effects) varies from 4 to $6 \mathrm{mg} / \mathrm{L} .^{24,28,29,70}$ However, these threshold values should not be used routinely to guide dosing, since a causal relationship between plasma concentration of voriconazole and clinical response remains to be elucidated. Even if an association between concentration and efficacy or toxic effects does exist, the pharmacokinetic parameter that will best predict clinical response $\left(C_{\min }, C_{\max }\right.$, or AUC) is unknown.

\section{INTRINSIC VARIABILITY AND OTHER CONFOUNDERS}

The possibility that the pharmacokinetic parameters are unpredictable, because of intrinsic variability or the presence of other confounding factors, must also be assessed..$^{37}$

\section{Saturable Metabolism}

In general, voriconazole exhibits a nonlinear pharmacokinetic profile, which is most probably attributable to its saturable hepatic clearance. ${ }^{20}$ In adult patients, plasma concentrations of the drug increase disproportionately, by about 3-fold with a $33 \%$ dosage increase. ${ }^{20,70,75}$ This phenomenon occurred when patients were given clinically recommended (usual) voriconazole doses of $100 \mathrm{mg}, 200 \mathrm{mg}$, and $300 \mathrm{mg}{ }^{20}$ This property of saturable metabolism may lead to variation both within and between individuals. Interestingly, saturable hepatic clearance was not observed in a pharmacokinetic study involving 35 immunocompromised children, as previously discussed. ${ }^{28}$

\section{Drug Interactions}

Because voriconazole is a known substrate for CYP2C9, CYP2C19, and CYP3A4, several drug-drug interactions are possible with other agents metabolized by similar routes. The concentration of voriconazole is reduced in the presence of rifampin, rifabutin, phentoin, and ritonavir, and is increased in the presence of omeprazole, cimetidine, erythromycin, and indinavir. ${ }^{13,78}$ TDM may be warranted if toxicity or lack of response because of a drug-drug interaction is suspected.

Voriconazole is also known to inhibit the same three isoenzymes, thereby increasing the concentrations of omeprazole, phenytoin, warfarin, rifabutin, and prednisolone. ${ }^{13}$ Elevated concentrations of cyclosporine, tacrolimus, and sirolimus through inhibition of CYP3A4 have also been demonstrated with concomitant voriconazole administration. ${ }^{13}$ This may carry substantial clinical implications, as many patients being treated with voriconazole for invasive fungal infections receive concurrent therapy with immunosuppressants. Considering 
these possible drug interactions, drug monitoring of the affected drug or empiric dosing adjustment may be indicated.

\section{DURATION OF THERAPY}

At this point, it is essential to determine whether the duration of drug therapy is sufficient for the patient to benefit from clinical pharmacokinetic monitoring. ${ }^{37}$

The appropriate duration of therapy for voriconazole or any antifungal agent for an invasive fungal infection is not well established. Given the high mortality and morbidity associated with fungal infections, and the inherent difficulty of eradicating fungal pathogens, treatment of such infections may last from weeks to months, depending on the type of pathogen, the site and extent of the infection, and the patient's immune status. For invasive pulmonary aspergillosis, the recommended treatment duration is a minimum of 6 to 12 weeks, whereas chronic pulmonary aspergillosis may require treatment with voriconazole for several months. ${ }^{16,40}$ Rarely would a patient be receiving voriconazole for less than 2 weeks, especially given that empiric therapy with voriconazole in febrile neutropenia is not recommended. In summary, if TDM is indicated (as determined by earlier steps in the algorithm shown in Figure 1), the duration of voriconazole therapy is adequate and appropriate to allow TDM to be performed and patient therapy to benefit.

\section{UTILITY OF DRUG MONITORING IN CLINICAL DECISION-MAKING}

Finally, the clinician must determine whether the results of the drug assay will make a significant difference in clinical decision-making (by providing more information than sound clinical judgement alone). ${ }^{37}$

Many trials have suggested a possible association between plasma concentration of voriconazole and the efficacy and toxic effects of the drug. However, because the available evidence does not support any definitive relation at this time, it is unlikely that routine TDM of voriconazole can provide any additional therapeutic advantage in the clinical setting. In addition, several other gaps in knowledge (e.g., sampling time for optimal drug monitoring, thresholds that correlate with clinical efficacy and toxic effects) must be filled before TDM of voriconazole can be fully utilized. As Brüggemann and others ${ }^{35}$ suggested in a recent review article, the indication to use voriconazole TDM as a means to ensure optimal drug concentrations after intravenousto-oral step-down is probably weak. Nonetheless, this approach is supported by the results of a randomized study of patients with invasive aspergillosis, in which $71 \%$ of the patients receiving voriconazole but only $58 \%$ of those receiving amphotericin B had treatment success at the 12-week follow-up, despite intravenous-to-oral therapy step-down (from $4 \mathrm{mg} / \mathrm{kg}$ IV twice daily to $200 \mathrm{mg}$ PO twice daily) after a median of 10 days of IV therapy, regardless of plasma concentration of the drug. ${ }^{39}$
However, selective monitoring of voriconazole concentration may be considered under certain circumstances when lack of response or toxic effects related to external and internal patient factors (e.g., drug interactions, CYP2C19 genetic polymorphism, hepatic impairment) are present or strongly suspected in a critically ill patient. An extremely low or high concentration of voriconazole in such a setting may help the clinician to rule out or verify a particular diagnosis and may provide guidance in making the most logical and clinically sound decision.

\section{CONCLUSIONS}

Voriconazole has demonstrated efficacy in the treatment of invasive fungal infections caused by a variety of fungal pathogens. It is preferred over amphotericin B for the treatment of aspergillosis, given its comparable efficacy and lower incidence of toxic effects. HPLC appears to be the most widely accepted analytic method for quantification of voriconazole concentration in the plasma, but in light of the requirement for specialized equipment and associated high costs, this type of assay is not readily accessible to all institutions. The wide variability in exposure to voriconazole, both within and between individuals, secondary to saturable metabolism, genetic polymorphism, drug interactions, disease state, and other pharmacokinetic factors provides the rationale for TDM. Duration of therapy with voriconazole for invasive fungal infections will generally last for weeks if not months, which allows adequate time to realize the benefits of TDM. However, the correlation between plasma concentrations of voriconazole and the drug's efficacy and toxic effects remain inconclusive. While a lower target threshold of 0.25 to $2 \mathrm{mg} / \mathrm{L}$ and an upper target of 4 to $6 \mathrm{mg} / \mathrm{L}$ have been suggested, studies to date have not been appropriately designed or powered to definitively determine any association. Routine TDM with voriconazole is therefore not recommended. On the contrary, clinicians should monitor patients for attributable signs and symptoms, such as resolution of serologic, clinical, or radiologic findings, as a means of determining the efficacy of antifungal therapy. Ultimately, under certain circumstances, such as the lack of response to therapy or occurrence of toxic effects, selective monitoring of voriconazole concentration, in concert with other available tools, may be considered to assist clinical decision-making. In such cases, TDM may offer some benefit, but clinicians should interpret the results with caution. Although the subject of voriconazole TDM has sparked much clinical and academic interest and discussion, a well-designed, randomized trial with fixed sampling time points may not be feasible and is unlikely to be performed, as it would be difficult to recruit study participants from this patient population and the sample would almost certainly be heterogeneous. 


\section{References}

1. Wisplinghoff H, Bischoff T, Tallent SM, Seifert H, Wenzel RP, Edmond MB. Nosocomial bloodstream infections in US hospitals: analysis of 24,179 cases from a prospective nationwide surveillance study. Clin Infect Dis 2004;39(3):309-317. Errata in: Clin Infect Dis 2004;39(7):1093. Clin Infect Dis 2005;40(7):1077.

2. Baddley JW, Stroud TP, Salzman D, Pappas PG. Invasive mold infections in allogeneic bone marrow transplant recipients. Clin Infect Dis 2001;32(9):1319-1324.

3. Marr KA, Carter RA, Crippa F, Wald A, Corey L. Epidemiology and outcome of mould infections in hematopoietic stem cell transplant recipients. Clin Infect Dis 2002;34(7):909-917.

4. Enoch DA, Ludlam HA, Brown NM. Invasive fungal infections: a review of epidemiology and management options. J Med Microbiol 2006;55 (Pt 7):809-818.

5. Meersseman W, Lagrou K, Maertens J, Van Wjingaerden E. Invasive aspergillosis in the intensive care unit. Clin Infect Dis 2007;45(2): 205-216.

6. Ostrosky-Zeichner L, Pappas PG. Invasive candidiasis in the intensive care unit. Crit Care Med 2006;34(3):857-863.

7. Baden LR, Katz JT, Fishman JA, Koziol C, DelVechhio A, Doran M, et al. Salvage therapy with voriconazole for invasive fungal infections in patients failing or intolerant to standard antifungal therapy. Transplantation 2003;76(11):1632-1637.

8. Goodwin ML, Drew RH. Angifungal serum concentration monitoring: an update. J Antimicrob Chemother 2008;61(1):17-25.

9. Lin SJ, Schranz J, Teutsch SM. Aspergillosis case-fatality rate: systematic review of the literature. Clin Infect Dis 2001;32(3):358-366.

10. Magill SS, Chiller TM, Warnock DW. Evolving strategies in the management of aspergillosis. Expert Opin Pharmacother 2008;9(2):193-209.

11. Dodds Ashley ES, Lewis R, Lewis JS, Martin C, Andes D. Pharmacology of systemic antifungal agents. Clin Infect Dis 2006;43:S28-S39.

12. Levêque D, Nivoix Y, Jehl F, Herbrecht R. Clinical pharmacokinetics of voriconazole. Int J Antimicrob Agents 2006;27(4):274-284

13. VFEND® I.V. (voriconazole) for injection, VFEND® tablets (voriconazole), VFEND® (voriconazole) for oral suspension [US physician prescribing information]. New York (NY): Roerig Division of Pfizer Inc; revised 2008 Mar [cited 2008 Sep 3]. Available from: http://media.pfizer.com/files/ products/uspi_vfend.pdf

14. Scott LJ, Simpson D. Voriconazole: a review of its use in the management of invasive fungal infections. Drugs 2007;67(2):269-298.

15. Perfect JR, Marr KA, Walsh TJ, Greenberg RN, DuPont B, de la TorreCisneros, et al. Voriconazole treatment for less-common, emerging, or refractory fungal infections. Clin Infect Dis 2003;36(9):1122-1131.

16. Walsh TJ, Aaissie EJ, Denning DW, Herbrecht R, Kontoyiannis DP, Marr $\mathrm{KA}$, et al. Treatment of aspergillosis: clinical practice guidelines of the Infectious Diseases Society of America. Clin Infect Dis 2008;46(3):327360

17. Briefing document for voriconazole (oral and intravenous formulations). Prepared for submission to US Food and Drug Administration, Food and Drugs Advisory Committee. Pfizer; 2001 Oct 4 [cited 2008 Sep 3]. Available from:http:/www.fda.gov/ohrms/dockets/ac/01/briefing/ 3792b2_01_Pfizer.pdf

18. Smith J, Safdar N, Knasinski V, Simmons W, Bhavnani SM, Ambrose PG, et al. Voriconazole therapeutic drug monitoring. Antimicrob Agents Chemother 2006;50(4):1570-1572.

19. Patterson BE, Coates PE. UK-109-496, a novel, wide spectrum triazole for the treatment of fungal infections: pharmacokinetics in man [abstract F78, 126]. In: Program and Abstracts of the 35th Annual Meeting of the Infectious Diseases Society of America; 1995; San Francisco (CA).

20. Purkins L, Wood N, Ghahramani P, Greenhalgh K, Allen MJ, Kleinermans D. Pharmacokinetics and safety of voriconazole following intravenous- to oral-dose escalation regimens. Antimicrob Agents Chemother 2002;46(8):2546-2553.

21. Hariprasad SM, Mieler WF, Holz ER, Gao H, Kim JE, Chi J, et al. Determination of vitreous, aqueous, and plasma concentration of orally administered voriconazole in humans. Arch Ophthalmol 2004;122(1):42-47.

22. Lutsar I, Roffey S, Troke P. Voriconazole concentrations in the cerebrospinal fluid and brain tissue of guinea pigs and immunocompromised patients. Clin Infect Dis 2003;37(5):728-732.
23. Mouas H, Lutsar I, Dupont B, Fain O, Herbrecht R, Lescure FX, et al.; Voriconazole/Bone Invasive Aspergillosis Study Group. Voriconazole for invasive bone aspergillosis: a worldwide experience of 20 cases. Clin Infect Dis 2005;40(8):1141-1147.

24. Denning DW, Ribaud P, Milpied N, Caillot D, Herbrecht R, Thiel E, et al. Efficacy and safety of voriconazole in the treatment of acute invasive aspergillosis. Clin Infect Dis 2002;34(5):563-571.

25. Trifilio S, Pennick G, Pi J, Zook J, Golf M, Kaniecki K, et al. Monitoring plasma voriconazole levels may be necessary to avoid subtherapeutic levels in hematopoietic stem cell transplant recipients. Cancer 2007;109(8): 1532-1535.

26. Pasqualotto AC, Shah M, Wynn R, Denning DW. Voriconazole plasma monitoring. Arch Dis Child 2008;93(7):578-581.

27. Boyd AE, Modi S, Howard SJ, Moore CB, Keevil BG, Denning DW. Adverse reactions to voriconazole. Clin Infect Dis 2004;39(8):1241-1244.

28. Imhof A, Schaer DJ, Schanz U, Schwarz U. Neurological adverse events to voriconazole: evidence for therapeutic drug monitoring. Swiss Med Wkly 2006;136(45-46):739-742.

29. Pascual A, Calandra T, Bolay S, Buclin T, Bille J, Marchetti O. Voriconazole therapeutic drug monitoring in patients with invasive mycoses improves efficacy and safety outcomes. Clin Infect Dis 2008;46(2):201-211.

30. Lewis RE. What is the "therapeutic range" for voriconazole. Clin Infect Dis 2008;46(2):212-214.

31. Purkins L, Wood N, Kleinermans D, Greenhalgh K, Nichols D. Effect of food on the pharmacokinetics of multiple-dose oral voriconazole. $\mathrm{Br} J$ Clin Pharmacol 2003;56 Suppl 1:17-23.

32. Walsh TJ, Karlsson MO, Driscoll T, Arguedas AG, Adamson P, Saez-Llorens X, et al. Pharmacokinetics and safety of intravenous voriconazole in children after single-or multiple-dose administration. Antimicrob Agents Chemother 2004;48(6):2166-2172.

33. Smith J, Andes D. Therapeutic drug monitoring of antifungals: pharmacokinetic and pharmacodynamic considerations. Ther Drug Monit 2008;30(2):167-172.

34. Hope WW, Billaud EM, Lestner J, Denning DW. Therapeutic drug monitoring for triazoles. Curr Opin Infect Dis 2008;21(6):580-586.

35. Brüggemann RJ, Donnelly JP, Aarnoutse RE, Warris A, Blijlevens N, Mouton JW, et al. Therapeutic drug monitoring of voriconazole. Ther Drug Monit 2008;30(4):403-411.

36. Howard A, Hoffman J, Sheth A. Clinical application of voriconazole concentrations in the treatment of invasive aspergillosis. Ann Pharmacother 2008;42(12):1859-1864.

37. Ensom MHH, Davis GA, Cropp CD, Ensom RJ. Clinical pharmacokinetics in the 21 st century. Does the evidence support definitive outcomes? Clin Pharmacokinet 1998;34(4):265-279.

38. Pappas PG, Andes D, Benjamin D Jr, Calandra TF, Edward JE Jr, Filer SG, et al. 2008 IDSA guidelines for invasive candidiasis [PowerPoint presentation]. Arlington (VA): Infectious Diseases Society of America; 2007 [cited 2008 Sep 3]. Available from: http://www.idsociety.org/WorkArea/ downloadasset.aspx?id=7818

39. Herbrecht R, Denning DW, Patterson T, Bennett JE, Greene RE, Oestmann JW, et al.; Invasive Fungal Infections Group of the European Organisation for Research and Treatment of Cancer and the Global Aspergillus Study Group. Voriconazole versus amphotericin B for primary therapy of invasive aspergillosis. $N$ Engl J Med 2002;347(6):408-415.

40. Sambatakou H, Dupont B, Lode H, Denning DW. Voriconazole treatment for subacute invasive and chronic pulmonary aspergillosis. Am J Med 2006;119(6):527.e17-527.e24.

41. Veroux M, Corona D, Gagliano M, Sorbello M, Macarone M, Cutuli M, et al. Voriconazole in the treatment of invasive aspergillosis in kidney transplant recipients. Transplant Proc 2007;39(6):1838-1840.

42. Schwartz S, Ruhnke M, Ribaud P, Corey L, Driscoll T, Comely OA. Improved outcome in central nervous system aspergillosis, using voriconazole treatment. Blood 2005;106(8):2641-2645.

43. Camuset J, Nunes H, Dombret MC, Bergeron A, Henno P, Philippe B, et al. Treatment of chronic pulmonary aspergillosis by voriconazole in nonimmunocompromised patients. Chest 2007;131(5):1435-1441.

44. Ally R, Schürmann D, Kreisel W, Carosi G, Aguirrebengoa K, Dupont B, et al.; Esophageal Candidiasis Study Group. A randomized, double-blind, double-dummy, multicenter trial of voriconazole and fluconazole in the treatment of esophageal candidiasis in immunocompromised patients. Clin Infect Dis 2001;33(9):1447-1454. 
45. Kullberg BJ, Sobel JD, Ruhnke M, Pappas PG, Viscoli C, Rex JH, et al. Voriconazole versus a regimen of amphotericin B followed by fluconazole for candidaemia in non-neutropenic patients: a randomised non-inferiority trial. Lancet 2005;366(9495):1435-1442.

46. Ostrosky-Zeichner L, Oude Lashof AML, Kullberg BJ, Rex JH. Voriconazole salvage treatment of invasive candidiasis. Eur J Clin Microbiol Infect Dis 2003;22(11):651-655.

47. Walsh TJ, Pappas P, Winston D, Lazarus HM, Petersen F, Raffalli J, Yanovich S, et al; National Institute of Allergy and Infectious Diseases Mycoses Study Group. Voriconazole compared wth liposomal amphotericin B for empirical antifungal therapy in patients with neutropenia and persistent fever. $N$ Engl J Med 2002;346(4):225-234. Erratum in: N Engl J Med 2007;356(7):760.

48. Jørgensen KJ, Gøtzsche PC, Johansen HK. Voriconazole versus amphotericin B in cancer patients with neutropenia. Cochrane Database Syst Rev 2006; (1):CD004707.

49. Spanakis EK, Aperis G, Mylonakis E. New agents for the treatment of fungal infections: clinical efficacy and gaps in coverage. Clin Infect Dis 2006;43(8):1060-1068. Erratum in: Clin Infect Dis 2006;43(9):1232.

50. Walsh TJ, Lutsar I, Driscoll T, Dupont B, Roden M, Ghahramani P, et al. Voriconazole in the treatment of aspergillosis, scedosporiosis and other invasive fungal infections in children. Pediatr Infect Dis J 2002;21(3): 240-248.

51. Cesaro S, Toffolutti T, Messina C, Calore E, Alaggio R, Cusinato R, et al. Safety and efficacy of caspofungin and liposomal amphotericin B, followed by voriconazole in young patients affected by refractory invasive mycosis. Eur J Haematol 2004;73(1):50-55

52. Cesaro S, Strugo L, Alaggio R, Cecchetto G, Rigobello L, Pillon M, et al. Voriconazole for invasive aspergillosis in onchohematological patients: a single-center pediatric experience. Support Care Cancer 2003;11(11):722727 .

53. Kolve H, Lehrnbecher TH, Ehlert K, Paulussen M, Bielack S, Vormoor J, et al. Safety, tolerance and plasma concentrations of voriconazole in immunocompromised pediatric patients [abstract]. Clin Microbiol Infect 2004;10 Suppl 3:40-41.

54. Hilliard T, Edwards S, Buchdahl R, Francis J, Rosenthal M, Balfour-Lynn I, et al. Voriconazole therapy in children with cystic fibrosis. J Cyst Fibros 2005;4(4):215-220.

55. Pascual A, Nieth V, Calandra T, Bille J, Bolay S, Decosterd LA, et al. Variability of voriconazole plasma levels measured by new highperformance liquid chromatography and bioassay methods. Antimicrob Agents Chemother 2007;51(1):137-143.

56. Perea S, Pennick GJ, Modak A, Fothergill AW, Sutton DA, Sheehan DJ, et al. Comparison of high-performance liquid chromatographic and microbiological methods for determination of voriconazole levels in plasma. Antimicrob Agennts Chemother 2000;44(5):1209-1213.

57. Chhun S, Rey E, Tran A, Lortholary O, Pons G, Jullien V. Simultaneous quantification of voriconazole and posaconazole in human plasma by high-performance liquid chromatography with ultra-violet detection. J Chromatogr B Analyt Technol Biomed Life Sci 2007;852(1-2):223-228.

58. Gage R, Stopher DA. A rapid HPLC assay for voriconazole in human plasma. J Pharm Biomed Anal 1998;17(8):1449-1453.

59. Khoschsorur GA, Fruehwirth F, Zelzer S. Isocratic high-performance liquid chromatographic method with ultraviolet detection for simultaneous determination of levels of voriconazole and itraconazole and its hydroxy metabolite in human serum. Antimicrob Agents Chemother 2005; 49(8):3569-3571.

60. Langman LJ, Boakye-Agyeman F. Measurement of voriconazole in serum and plasma. Clin Biochem 2007;40(18):1378-1385.

61. Péhourcq F, Jarry C, Bannwarth B. Direct injection HPLC micro method for the determination of voriconazole in plasma using an internal surface reversed-phase column. Biomed Chromatogr 2004;18(9):719-722.

62. Pennick GJ, Clark M, Sutton DA, Rinaldi MG. Development and validation of a high-performance liquid chromatography assay for voriconazole. Antimicrob Agents Chemother 2003;47(7):2348-2350.

63. Shihabi ZK. Simple assay for voriconazole in serum by HPLC. J Liq Chromatogr Relat Technol 2008;31(2):263-268.

64. Stopher DA, Gage R. Determination of a new antifungal agent, voriconazole, by multidimensional high-performance liquid chromatography with direct plasma injection onto a size-exclusion column. J Chromatogr B Biomed Sci Appl 1997;691(2):441-448.
65. Wenk M, Droll A, Krähenbühl S. Fast and reliable determination of the antifungal drug voriconazole in plasma using monolithic silica rod liquid chromatography. J Chromatogr B Analyt Technol Biomed Life Sci 2006;832(2):313-316.

66. Egle H, Trittler R, König A, Kümmerer K. Fast, fully automated analysis of voriconazole from serum by LC-LC-ESI-MS-MS with parallel columnswitching technique. J Chromatogr B Analyt Technol Biomed Life Sci 2005;814(2):361-367.

67. Keevil BG, Newman S, Lockhart S, Howard SJ, Moore CB, Denning DW. Validation of an assay for voriconazole in serum samples using liquid chromatography-tandem mass spectrometry. Ther Drug Monit 2004; 26(6):650-657.

68. Vogeser M, Schiel X, Spöhrer U. Quantification of voriconazole in plasma by liquid chromatography-tandem mass spectrometry. Clin Chem Lab Med 2005;43(7):730-734.

69. Tan K, Brayshaw N, Tomaszewski K, Troke P, Wood N. Investigation of the potential relationships between plasma voriconazole concentrations and visual adverse events or liver function test abnormalities. J Clin Pharmacol 2006;46(2):235-243.

70. Trifilio S, Ortiz R, Pennick G, Verma A, Pi J, Stosor V, et al. Voriconazole therapeutic drug monitoring in allogeneic hematopoietic stem cell transplant recipients. Bone Marrow Transplant 2005;35(5):509-513.

71. Mikus G, Schöwel V, Drzewinska M, Rengelshausen J, Ding R, Riedel $\mathrm{KD}$, et al. Potent cytochrome P450 2C19 genotype-related interaction between voriconazole and the cytochrome P450 3A4 inhibitor ritonavir. Clin Pharmacol Ther 2006;80(2):126-135.

72. Eiden C, Peyrière H, Cociglio M, Djezzar S, Hansel S, Blayac JP, et al. Adverse effects of voriconazole: analysis of the French Pharmacovigilance Database. Ann Pharmacother 2007;41(5):755-763.

73. Ascioglu S, Rex JH, de Pauw B, Bennett JE, Bille J, Crokaert F, et al.; Invasive Fungal Infections Cooperative Group of the European Organization for Research and Treatment of Cancer; Mycoses Study Group of the National Institute of Allergy and Infectious Diseases. Defining opportunistic invasive fungal infections in immunocompromised patients with cancer and hematopoietic stem cell transplants: an international consensus. Clin Infect Dis 2002;34(1):7-14.

74. Ikeda Y, Umemura K, Kondo K, Sekiguchi K, Miyoshi S, Nakashima M. Pharmacokinetics of voriconazole and cytochrome P450 2C19 genetic status. Clin Pharmacol Ther 2004;75(6):587-588.

75. Lazarus HM, Blumer JL, Yanovich S, Schlamm H, Romero A. Safety and pharmacokinetics of oral voriconazole in patients at risk of fungal infection: a dose escalation study. J Clin Pharmacol 2002;42(4):395-402.

76. Peng LW, Lien YHH. Pharmacokinetics of single, oral-dose voriconazole in peritoneal dialysis patients. Am J Kidney Dis 2005;45(1):162-166.

77. Fuhrmann V, Schenk P, Jaeger W, Miksits M, Kneidinger N, Warszawska J, et al. Pharmacokinetics of voriconazole during continuous venovenous haemodiafiltration. J Antimicrob Chemother 2007;60(5):1085-1090.

78. Liu P, Foster G, Gandelman K, LaBadie RR, Allison MJ, Gutierrez MJ, et al. Steady-state pharmacokinetic and safety profiles of voriconazole and ritonavir in healthy male subjects. Antimicrob Agents Chemother 2007;51(10):3617-3626.

I fan Kuo, BSc(Pharm), PharmD, ACPR, was, at the time of writing, a student in the Faculty of Pharmaceutical Sciences, University of British Columbia. She is now a Clinical Pharmacy Specialist at St Paul's Hospital, Vancouver, British Columbia.

Mary H H Ensom, PharmD, FASHP, FCCP, FCSHP, FCAHS, is Professor and Director, Doctor of Pharmacy Program, Faculty of Pharmaceutical Sciences, and Distinguished University Scholar, University of British Columbia, and Clinical Pharmacy Specialist with the Children's and Women's Health Centre of British Columbia, Vancouver, British Columbia. She is also the Editor of the CJHP.

\section{Address correspondence to:}

\section{Dr Mary H H Ensom}

Pharmacy Department (OB7)

Children's and Women's Health Centre of British Columbia

4500 Oak Street

Vancouver BC V6H 3N1

e-mail: ensom@interchange.ubc.ca 